\title{
System Development from Organic Solvents to Ionic Liquids for Synthesiz- ing Ascorbyl Esters with Conjugated Linoleic Acids
}

\author{
Zhiyong Yang ${ }^{1}$, Lise Schultz ${ }^{2}$, Zheng Guo ${ }^{1}$, Charlotte Jacobsen ${ }^{2}$ and Xuebing $\mathrm{Xu}^{1, *}$ \\ ${ }^{I}$ Department of Engineering, Aarhus University, DK-8000 Aarhus C, Denmark \\ ${ }^{2}$ National Food Institute, Technical University of Denmark, DK-2800 Kgs. Lyngby, Denmark
}

\begin{abstract}
The aim of this paper is to screen suitable reaction systems for the modification of antioxidants through enzymatic synthesis. Enzymatic esterification of ascorbic acid with conjugated linoleic acid (CLA) was investigated as a model. Four organic solvents and five different enzymes were evaluated. Results show that only Novozym ${ }^{\circledR} 435$ turned out to be a useful enzymatic preparation for the production of ascorbyl-CLA ester. The optimum reaction conditions in the organic solvent system were $4 \mathrm{~h}$ at $55^{\circ} \mathrm{C}$ and at a molar ratio of 5 (CLA/ascorbic acid). The esterification reaction was transferred to an ionic liquid system for the purpose of improving solubility of the polar substrate and avoiding the application of organic solvents. From screening experiments, it was evident that only methyltrioctylammonium triflouroacetate ( $t \mathrm{O}-$ MA-TFA) could provide a proper reaction environment for production of ascorbyl-CLA ester when using Novozym ${ }^{\circledR} 435$ as biocatalyst. It was possible to significantly increase the productivity $(150 \mathrm{~g} / \mathrm{l})$ through the increase of ascorbic acid solubility in ionic liquids by super saturation together with the increase of reaction temperature to $70^{\circ} \mathrm{C}$, far beyond than that in organic solvents $(35 \mathrm{~g} / \mathrm{l})$ after preliminary optimizations for both systems.
\end{abstract}

Keywords: Ascorbic acid, CLA, Organic solvents, Ionic liquids, Esterification.

\section{INTRODUCTION}

An increasing amount of evidence compiled over the last 30 years, supports the nutritional benefits of dietary $\mho-3$ polyunsaturated fatty acids (PUFAs), which present in high amounts in marine oil [1]. However, $\mho-3$ PUFAs are highly susceptible to oxidative deterioration because of a high degree of unsaturated nature, and it will lead to the formation of unpleasant fishy off-flavors, reactive free radicals, and aldehydes. Oxidative deterioration seems to be particularly prominent in emulsions and complex food systems, and the particular mechanisms of oxidation can differ significantly between different food emulsion systems [2]. Moreover, the efficacy of antioxidants seems to be influenced by their localization in the food systems, which is dependent on the polarity of the antioxidant and on the emulsifier used. Therefore, it is necessary to develop new antioxidants based on natural sources with improved physical properties. These antioxidants are designed to be placed where they are needed and to have the right anti-oxidative properties required in the particular food system (e.g. free radical scavenging or metal chelating properties).

Ascorbic acid (Vitamin C) is an antioxidant which can be widely found in nature, however it is a hydrophilic compound and difficult to apply in cosmetics or in the presence of fats and oils. A simple method is to esterify ascorbic acid with a fatty acid, which will result in an amphiphilic molecule which will not only improve solubility of ascorbic acid

*Address correspondence to this author at Department of Engineering, Aarhus University, Gustav Wieds Vej 10C, DK-8000 Aarhus C, Denmark; Tel: +45 89425089; Fax: +45 86123178; E-mail: xu@mb.au.dk in hydrophobic media but will also enhance its radical scavenging performance [3]. The majority of the previous investigations concerns the esterification of ascorbic acid with palmitic, oleic or linoleic acids in organic solvent systems and resulted in relatively lower productivities [3-7]. This paper investigates the enzymatic esterification of ascorbic acid with conjugated linoleic acid (CLA). In recent years, the nutritional benefits of CLA have been studied extensively, and especially the weight reducing and cancer suppressing effects have received significant attention [8,9]. Additionally, antioxidant properties of CLA have also been proposed. Even though the radical scavenging activity of CLA was lower than those of the commercial antioxidants such as $\alpha$ tocopherol, ascorbic acid and BHT, a concentration dependant reduction of free radicals in model assays were observed [10]. Likewise, it has been shown that the oxidative stability of eicosapentaenoic acid (EPA) was increased by esterification with ascorbic acid [11]. The present investigations concern the optimization of the enzymatic esterification in a solvent system with respect to enzymes, solvents, reaction temperatures, and molar ratios for the purpose of increase of volumetric productivity.

Application of ionic liquids as reaction medium for enzymatic synthesis is becoming increasingly widespread. However, very few studies on the esterification of ascorbic acid in ionic liquids have been published [12]. A very recent study on the synthesis of ascorbyl oleate in ionic liquids has been conducted by Adamczak M and Bornscheuer UT [13], where they showed that a high production of ascoybyl oleate can be achieved in ionic solvent systems. In contrast to these previous studies, we have studied the use of mixture systems between ionic liquids and organic solvents, where much 
higher volumetric productivity has been demonstrated [14]. In order to create the possibility of avoiding the application of organic solvents, this paper investigates and compares the change of esterification of ascorbic acid with CLA, when transferred to an ionic liquid system from organic solvent systems. Five ionic liquids were selected and screened for their ability to provide a useful environment for the enzymatic reaction and the reaction conditions in the selected ionic liquid systems were optimized to increase product concentration.

The present study evaluates the organic solvent system first based on the state of the art, and then looks further into the pure ionic liquid system with a focus particularly on volumetric productivity. A comparison can then be made to demonstrate the possible pros and cons of the two systems for the enzymatic synthesis of ascorbyl esters.

\section{MATERIALS AND METHODS}

\section{Chemical and Reagents}

L-Ascorbic acid (99\%), molecular sieves (3 $\AA$, 4-8 mesh), free fatty acids $(97 \%-99 \%)$ and organic solvents $(>96 \%)$ were purchased from Sigma-Aldrich Co. (St Louis, USA). Conjugated linoleic acid (CLA) with $>80 \%(9 Z, 11 E)$ and $(10 E, 12 Z)$-isomer content, was obtained from Congnis Deutschland GmbH (Manheim, Germany). Mixture of DHA/EPA (5:1) was purchased from Promega A/S, Denmark, and it contains $60 \%$ of polyunsaturated fatty acid. All ionic liquids with minimum $98 \%$ of purity were purchased from Solvent Innovation GmbH (Köln, Germany). Methyltrioctylammonium trifluoroacetate ( $t$ OMA-TFA) with $99 \%$ of purity was from Merck KGaA (Darmstadt, Germany). Novozym $^{\circledR} 435$, Lipozyme ${ }^{\circledR}$ RM IM, and Lipozyme ${ }^{\circledR}$ TL IM were provided by Novozymes A/S (Bagsvaerd, Denmark). Lipase AK 20 and Lipase PS 30 were provided by Amano (Nagoya, Japan). All other chemicals and solvents were analytical grade.

\section{Typical Experimental Procedure}

A traditional solvent system was composed of ascorbic acid $(2.1 \mathrm{mmol})$, CLA $(8.5 \mathrm{mmol})$, molecular sieves $(0.75 \mathrm{~g})$ and $15 \mathrm{ml}$ of organic solvent. Reactions were initiated at 55 ${ }^{\circ} \mathrm{C}$ and $400 \mathrm{rpm}$ by adding $410 \mathrm{mg}$ enzyme. Screening of enzymes was performed in tert-butanol under the same conditions demonstrated above. The conditions used in the traditional solvent system were also applied for examination of initial concentration of ascorbic acid and molar ratio between CLA and ascorbic acid. Reaction mixtures were continuously stirred at atmospheric pressure and the temperature was controlled by a thermostatic water bath.

In an ionic liquid system, reactions were conducted at $55^{\circ} \mathrm{C}$ in the presence of $282 \mathrm{mg}$ Novozym ${ }^{\circledR} 435$ instead. Systems was composed of ascorbic acid (1.22 mmol), CLA (6.09 $\mathrm{mmol})$ and ionic liquids $(0.5 \mathrm{ml})$. Reaction mixtures were stirred at $300 \mathrm{rpm}$ under $3 \mathrm{mbar}$ vacuums, while pressure was controlled by a vacuum-pump (VWR PC301). Effects of temperature (from $55^{\circ} \mathrm{C}$ to $70{ }^{\circ} \mathrm{C}$ ) and initial concentration of ascorbic acid (from $0.81 \mathrm{M}$ to $2.44 \mathrm{M}$ ) were studied base on the same condition as above.

\section{HPLC Analysis}

Samples $(20 \mu 1)$ were taken from the reaction mixture at regular intervals, dissolved in $1 \mathrm{ml}$ dimethyl sulphoxide (DMSO), filtered (PFTE membrane, $0.45 \mu \mathrm{m}$, Subware, Hillerød, Denmark) and analyzed by HPLC with UVdetection. HPLC analysis was conducted by using a Hypersil C18 column $(250 \times 4.6 \mathrm{~mm}, 5 \mu \mathrm{m}$, Supelcosil Inc., Bellefonte, PA) in an Agilent HPLC system. The system is equipped with an ultraviolet diode-array detector (UV-DAD), an autosampler, an online degasser and a column heater. The eluents were composed of solvent A (methanol and acetonitrile, $50 / 50(\mathrm{v} / \mathrm{v})$ ), and solvent B (water with $1 \mathrm{wt} \%$ of phosphoric acid). A $2 \mu 1$ volume of the diluted reaction mixture was injected and separated at $15^{\circ} \mathrm{C}$ with a flow rate of $1 \mathrm{ml} / \mathrm{min}$. The elution gradient was as follows: start with $80 \%$ of solvent $\mathrm{A}$, and then increased to $100 \%$ over 15 minutes. This condition was maintained for $2 \mathrm{~min}$ and then brought back to initial conditions over 3 mins. Products were detected under $240 \mathrm{~nm}$ UV light. The formation of esterified product was determined as g CLA ascorbate equivalents/1 (APE) in each reaction batch. All analyses were conducted in triplicate and the averages $(\overline{A P E})$ were used for evaluation. The relative standard deviations $(| \pm \mathrm{SD}| * 100 / \overline{A P E})$ were below $5.3 \%$.

\section{Solubility Calculation of Ascorbic Acid Assisted by COSMO-RS}

Based on an earlier study [15], a commercial program, COSMO-RS (COSMOlogic GmbH \& Co KG, Leverkusen, Germany), was employed to calculate the solubility of ascorbic acid in ionic liquids or other solvents based on a quantum chemistry model. In general, generation of molecular COSMO files was implemented on Turbomole 5.8. Infinite dilution activity coefficients were used for solubility calculations of ascorbic acid in ionic liquids with a non-iterative mode on CosmothermX 2.2. In order for the comparison, we also calculated the solubility of ascorbic acid in the organic solvents used in above.

According to the prediction by the software, it shows solubility of ascorbic acid in tOMA.TFA and ECOENG 218 / EMIm OS is much higher than other ionic liquids and organic solvents $-100 \mathrm{~g}$ of each these two ionic liquids can dissolve more than $15 \mathrm{~g}$ of ascorbic acid. ECOENG $21 \mathrm{M}$ is seemed to have some solubility to ascorbic acid (about $6 \mathrm{~g}$ in $100 \mathrm{~g}$ ionic liquid), but BMIm PF6 and BMIm BF4 are only seemed to have minor solubility. In organic solvents, it was predicted that solubility of ascorbic acid in acetone $>$ tertbutanol > 2-methyl-2-butanol, and ascorbic acid is hardly dissolved in hexane (Table 1).

\section{RESULTS AND DISCUSSIONS}

\section{Enzyme Screening in Organic Solvents}

There have been a number of studies to apply solvent systems for such esterifications previously $[3,15]$. Based on these studies, we proposed to make a practical evaluation in terms of volumetric productivity. This aspect was not clear in previous researches. We first made an evaluation of available immobilized lipases, followed by an evaluation of sol- 
Table 1. Predicted Solubility of Ascorbic Acid and CLA in Different Ionic Liquids and Solvents at $25{ }^{\circ} \mathrm{C}^{a}$

\begin{tabular}{|c|c|c|}
\hline \multirow{2}{*}{ Solvent } & \multicolumn{2}{|c|}{ Predicted Solubility (g/100g Ionic Liquid or Solvent) of } \\
\hline & Ascorbic Aicd & CLA \\
\hline tOMA $\cdot \mathrm{TFA}^{\mathrm{b}}$ & $>15^{\mathrm{c}}$ & $>15^{\mathrm{c}}$ \\
\hline ECOENG $218 /$ EMIm OS $^{\mathrm{b}}$ & $>15^{\mathrm{c}}$ & $>15^{\mathrm{c}}$ \\
\hline ECOENG $21 \mathrm{M}^{\mathrm{b}}$ & 6.0 & $>15^{\mathrm{c}}$ \\
\hline BMIm PF $6^{\mathrm{b}}$ & 0.6 & 0.2 \\
\hline $\mathrm{BMIm} \mathrm{BF} 4^{\mathrm{b}}$ & 0.4 & 1.1 \\
\hline Acetone & $<10^{\mathrm{c}}$ & Soluble \\
\hline tert-butanol & 4.99 & Soluble \\
\hline 2-methyl-2-butanol & 3.2 & Soluble \\
\hline Hexane & 0 & Soluble \\
\hline
\end{tabular}

${ }^{a}$ Calculated by COSMO-RS. See Method Section for details.

${ }^{b} t$ OMA.TFA: methyl-trioctyl-ammonium; ECOENG 218/EMIm OS: 1-ethyl-3-methyl-imidazolium n-octylsulfat; ECOENG 21M: 1-ethyl-3-methyl-imidazolium 2(2methoxyethoxy)-ethylsulphate; BMIm PF6: 1-butyl-3-methyl-imidazolium hexafluorophosphate; BMIm BF4: 1-butyl-3-methyl-imidazolium tetrafluoroborate

${ }^{c}$ Predictions using COSMO-RS were poor in these cases.

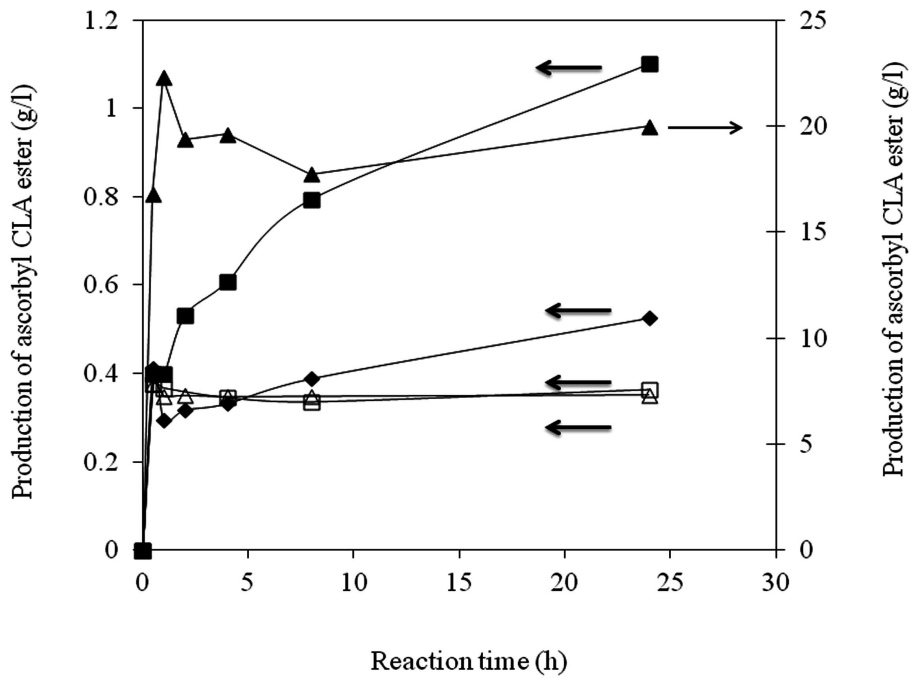

Fig. (1). Enzyme screening in a selected reaction system with tert-butanol as solvent. Novozym ${ }^{\circledR} 435$ ( $\left.\mathbf{\Delta}\right)$, Lipozyme ${ }^{\circledR}$ RM IM (®), Lipozyme $^{\circledR}$ TL IM $(\bullet)$, Lipase AK $20(\square)$ and Lipase PS $30(\Delta)$ were studied. Reaction conditions: $2.1 \mathrm{mmol}$ ascorbic acid and $8.5 \mathrm{mmol}$ CLA were dissolved in $15 \mathrm{ml}$ tert-butanol. Reactions were conducted in jacketed reactors at $55^{\circ} \mathrm{C}$ and $400 \mathrm{rpm}$ with the presence of $0.75 \mathrm{~g}$ molecular sieves.

vents. Fig. (1) shows the transient changes in the conversion to CLA L-ascorbate ester through condensation of CLA and ascorbic acid catalyzed by five different immobilized lipases. Results showed the esterification of ascorbic acid with CLA in tert-butanol was only efficient when used Novozym ${ }^{\circledR} 435$ as a catalyst (Fig. 1). Application of Lipozyme ${ }^{\circledR}$ RM IM produced small amounts of the desired product, whereas Lipozyme $^{\circledR}$ TL IM, Lipase AK20 and Lipase PS30 were not efficient at all. It is generally known Novozym ${ }^{\circledR} 435$ is the best lipase for esterifications in organic solvents. However, we can see from this study that there was a large difference between Novozym ${ }^{\circledR} 435$ and the rest selected lipase $(20$ times). This has not been previously reported. The initial tests also indicated that the equilibrium was reached within/after four hours at $55^{\circ} \mathrm{C}$ (Fig. 1).

\section{Organic Solvents Screening and Influence of Initial Con- centration of Ascorbic Acid}

Fig. (2) shows the esterification effect of Novozym ${ }^{\circledR} 435$ in four different organic solvents. A high production was obtained in both tert-butanol and acetone, but only a low amount of product was formed in reaction using 2-methyl-2butanol. The esterification reaction mediated by Novozym ${ }^{\circledR}$ 435 did not take place in hexane at all (Fig. 2). These results are consistent with previous studies, which showed a good conversion in both acetone and tert-butanol. Likewise, these studies investigating the enzymatic synthesis of ascorbylesters showed that no reaction was observed in hexane [3, 16]. The superior performance of the intermediate hydrophilic solvents was likely due to increased solubility of 


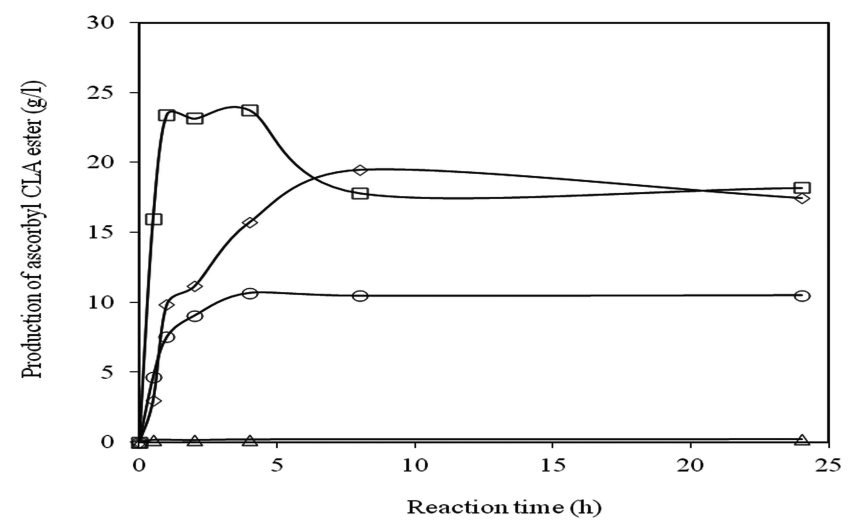

Fig. (2). Effects of organic solvents on enzymatic esterification. Reaction conditions: $2.1 \mathrm{mmol}$ ascorbic acid and $8.5 \mathrm{mmol}$ CLA were dissolved in $15 \mathrm{ml}$ tert-butanol $(\square)$, acetone ( ), 2-methyl-2-butanol (O), or n-hexane $(\triangle)$. Reactions were initiated by adding 410 mg Novo$\mathrm{zym}^{\circledR} 435$. Other reaction conditions were the same as described in methods section.

ascorbic acid in these solvents compared to hydrophobic solvents as predicted by COSMO (Table 1). On the other hand, highly hydrophilic solvents may dissolve the water, which is otherwise necessary to keep the enzyme in its active configuration. This hypothesis was supported by further experiments, which showed that increasing ascorbic acid concentrations above saturation limits in the tert-butanol system significantly increased product concentration. Initially, a concentration of $10 \mathrm{~g}$ ascorbic acid/1 gave a productivity of $8.3 \pm 0.02 \mathrm{~g} / \mathrm{l}$, whereas increasing the ascorbic acid concentration to $25 \mathrm{~g} / \mathrm{l}$ and $50 \mathrm{~g} / \mathrm{l}$ increased the productivity to $26.1 \pm 0.6$ and $32.3 \pm 0.2 \mathrm{~g} / \mathrm{l}$, respectively (Fig. 3). As indicated in this situation, the maximum productivity is hampered in the scale of $35 \mathrm{~g} / \mathrm{l}$, where excessive ascorbic acid is used which has brought problem for the handling of the solid existing system.

\section{Free Fatty Acids Screening}

A further study was carried on using a wide range of free fatty acid with different carbon length or unsaturated state. The purpose of this study was to investigate the esterification rate of ascorbic acid with different free fatty acid. Serials of reactions were done in tert-butanol using Novozym ${ }^{\circledR} 435$ as a catalyst. Six kinds of free fatty acids (FFA) were chosen for study, which included caprylic acid (C8), lauric acid (C12), palmitic acid (C16), oleic acid (C18:1), linoleic acid (C18:2), CLA and EPA/DHA (C20:5/CC22:6). Results show that the length of carbon chain and the number of double bond had great influence on the esterification rate with ascorbic acid (Fig. 4). It appears that shorter carbon chains of free fatty acids have higher esterification rate. The initial reaction rate of caprylic acid with ascorbic acid was $10.9 \mathrm{mg} / \mathrm{ml} / \mathrm{h}$. However, when longer carbon chains of free fatty acids were used, the initial reaction rate decreased steadily. For example, the initial reaction rate of lauric acid, palmitic acid and oleic acid were $9.5 \mathrm{mg} / \mathrm{ml} / \mathrm{h}, 5 \mathrm{mg} / \mathrm{ml} / \mathrm{h}$ and $0.4 \mathrm{mg} / \mathrm{ml} / \mathrm{h}$ respectively. On the other hand, the initial reaction rate of linoleic acid was $5.9 \mathrm{mg} / \mathrm{ml} / \mathrm{h}$, which is much higher than that of oleic acid. This observation indicates that PUFAs may favor the esterification reaction. This hypothesis was further supported when mixture of PUFAs (EPA/DHA) were used as a reaction substrate, which initial reaction rate was $1.8 \mathrm{mg} / \mathrm{ml} / \mathrm{h}$, and we all have known that EPA/DHA has a longer length and more double bonds on the carbon chain than oleic acid. What is worth noting is that the initial ration rate of CLA was significant higher than other free fatty acid $(33.6 \mathrm{mg} / \mathrm{ml} / \mathrm{h})$. This is probably due to the conjugated double bond and high UV absorbency of CLA.

\section{Influence of Molar Ratio of Substrates}

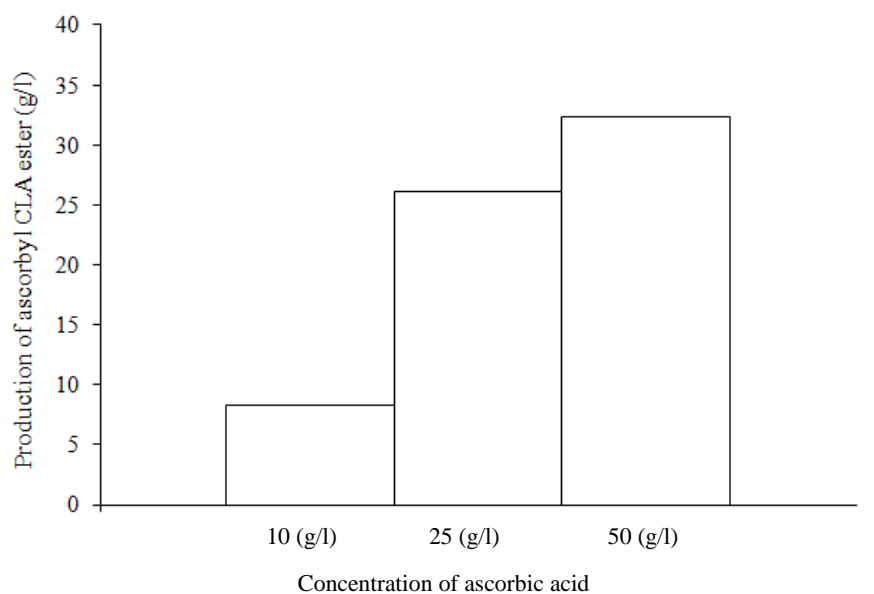

Fig. (3). Effects of initial concentration of ascorbic acid on the production of conjugated ester. Concentrations of ascorbic acid were $10 \mathrm{~g} / 1$ $(56.8 \mathrm{mM}), 25 \mathrm{~g} / \mathrm{l}(142 \mathrm{mM})$, and $50 \mathrm{~g} / \mathrm{l}(284 \mathrm{mM})$ respectively. Reactions were carried out in $15 \mathrm{ml}$ tert-butanol at $55^{\circ} \mathrm{C}$ and $400 \mathrm{rpm} .15 \%$ of Novozym ${ }^{\circledR} 435$ was used as catalyst. Molar ratio between ascorbic acid and CLA was 1:5. 
The influence of the molar ratio between acyl donor and ascorbic acid were initially investigated in the interval $\mathrm{R}$ (CLA/ascorbic acid) from 1 to 10 . A four-fold increase was observed when increasing the ratio from 1 to 5 , but only minor increases were observed between 5 and 10 (Fig. 5). The optimum ratio was subsequently determined to be 5 by the response surface modeling (detail study omitted). These results agree with previous studies of ascorbic acid esterification performed in acetone at $50{ }^{\circ} \mathrm{C}$, where a linear increase between $\mathrm{R}$ and equilibrium conversion was observed until $\mathrm{R}$ was equal to 5 [5].

\section{Ionic Liquids Screening}

In general, the major drawback for organic solvents was the low solubility of ascorbic acid, which was the bottleneck for the improvement of the volumetric productivity, even though certain super saturation did improve the productivity significantly as shown above. It is still advisable that a higher solubility should be achieved. For this concern, we investigated the possibility of several ionic liquids that usually have better solubility [14]. Calculations of the solubility of ascorbic acid and CLA were performed for eleven different ionic liquids by COSMO-RS (Leverkusen, Germany). Five of these ionic liquids seemed to have some potential solubilization with respect to ascorbic acid and CLA (Table 1), and were therefore tested as reaction medium for the enzymatic esterification.

The results showed that only $t \mathrm{OMA} \cdot \mathrm{TFA}$ could provide a proper reaction environment for the enzymatic esterification and resulted in useful levels of ascorbyl-CLA ester. About $11 \mathrm{~g} / 1$ of ascorbyl-CLA ester was achieved when reaction was carried out at $55^{\circ} \mathrm{C}$ in $t \mathrm{OMA} \cdot \mathrm{TFA}$ On the other hand, BMIm BF4, BMIm PF6, ECOENG 218/EMIm OS and ECOENG $21 \mathrm{M}$ resulted in only minor formation of the ascorbyl-CLA esters (1-5 g/l) when reactions were carried out under the same conditions as in $t \mathrm{OMA} \cdot \mathrm{TFA}$. Those four ionic liquids which gave lower production of ester were hence not included in the following optimization of the reaction system (Fig. 6).

The highest production obtained in the $t \mathrm{OMA} \cdot \mathrm{TFA}-$ system was in accordance with the calculated solubility values (Table 1). Ascorbic acid had a significantly highest solubility in $t$ OMA.TFA compared to other ionic liquids. CLA also had good solubility in $t \mathrm{OMA} \cdot \mathrm{TFA}$, and hence the highest production was obtained with $t \mathrm{OMA} \cdot \mathrm{TFA}$ as a reaction

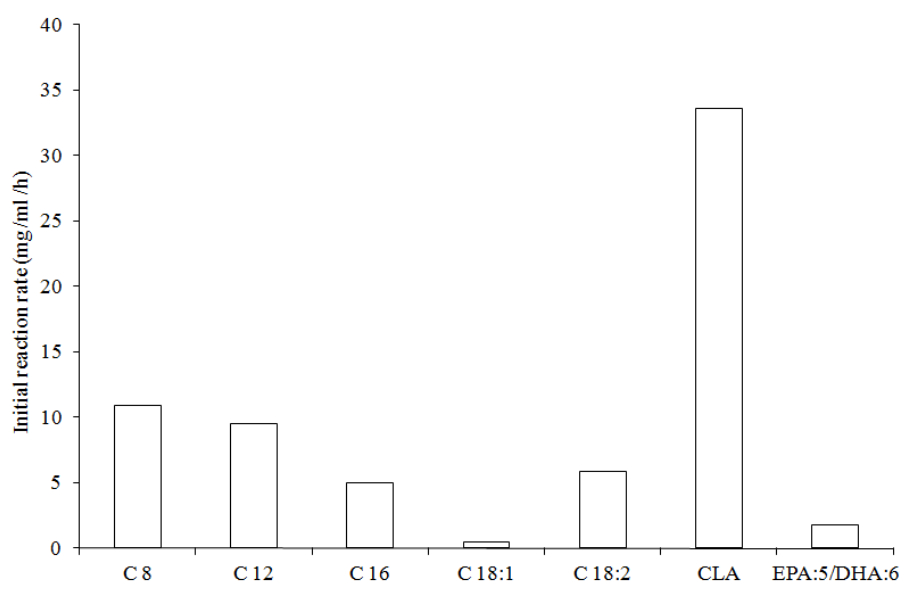

Fig. (4). Screening of free fatty acid. $2.1 \mathrm{mM}$ of ascorbic acid was mixed with free fatty acids in the molar ratio of 1 to 5 . Reactions were carried out in tert-butanol at $55^{\circ} \mathrm{C}$ using Novozym ${ }^{\circledR} 435$ as catalyst.

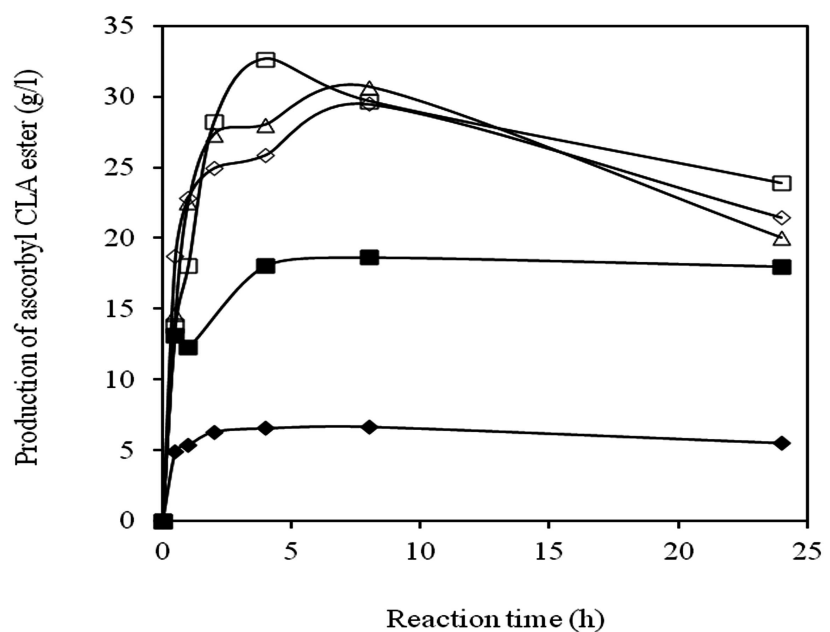

Fig. (5). Screening of molar ratio between ascorbic acid and CLA. Concentration of ascorbic acid was fixed to $2.1 \mathrm{mM}$. CLA was various from $2.1 \mathrm{mM}$ to $21 \mathrm{mM}$ to get molar ratio of 1:1 $\bullet), 2.5: 1(\bullet), 5: 1(\Delta), 7.5: 1()$, and 10:1 $(\square)$. All reactions were carried out in $15 \mathrm{ml}$ tertbutanol at $55{ }^{\circ} \mathrm{C}$ and $400 \mathrm{rpm}$ using $15 \%$ Novozym $^{\mathbb{B}} 435$ according to weight load. 


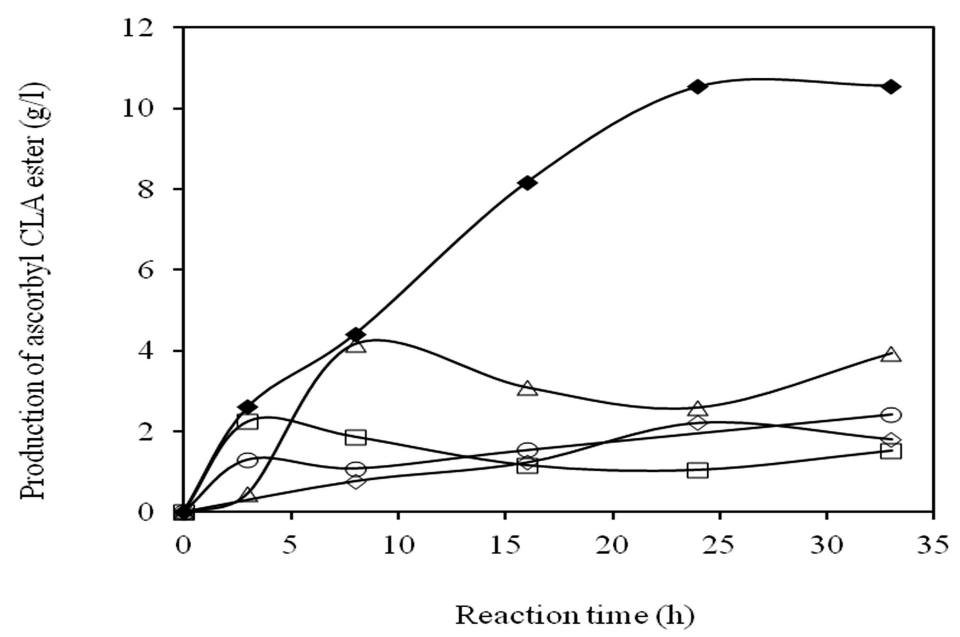

Fig. (6). Ionic liquids screening. Reactions were carried out at $55{ }^{\circ} \mathrm{C}$ under vacuum $\left(3\right.$ mbar) and $15 \%$ of Novozym ${ }^{\circledR} 435$ was applied. Ascorbic acid $(0.41 \mathrm{mmol} / \mathrm{ml})$ was mixed with CLA $(2 \mathrm{mmol} / \mathrm{ml})$ to give a molar ratio of 1:5. Five ionic liquids were evaluated: $t \mathrm{OMA} \cdot \mathrm{TFA}$ $(\bullet)$, ECOENG 218/ EMIm OS (O), ECOENG 21M ( $)$, BMIm PF6 ( $\triangle$ ), BMIm BF4 ( ).

medium for the esterification. ECOENG 218/EMIM.OS also has very good solubility for ascorbic acid and CLA, but application of this ionic liquid did not result in any significant formation of ascorbyl-CLA ester. This illustrates that solubility of substrates is not the only factor influencing efficiency of enzyme in ionic liquid systems. Important factors which can affect the catalytic activity of enzyme also include the ability of the ionic liquid to bind water, ionic interactions between the ionic liquid, and the enzyme according to previous studies $[17,18]$. Furthermore, we speculated that the amphiphilic nature and hence potential surface active properties of the n-octyl sulphate anion might affect its behavior as a reaction medium. Molecular interaction between the anion and the fatty acid CLA might occur, and subsequently reduce the availability of the CLA to the enzyme, which again would reduce the production.

The production of ascorbyl-CLA ester obtained by using BMIM BF4 was much lower than what had been obtained in a previous study investigating the esterification of ascorbic acid using palmitic acid [12]. In the present study, the amount of ascorbic acids and fatty acids were 12 and 51 times higher, respectively, whereas dosage of the enzyme was 6 times higher, but still only a very limited amount of ascorbyl ester was formed. The results indicate that the final production is affected by the type of fatty acids used. Even though BMIM BF4 is a hydrophilic ionic liquid, the solubility of glucose has been shown to be very low [19]. Likewise, our calculated solubility of ascorbic acid was also low. This probably contributed to the low production observed. Finally, it also seems that, in contrast to BMIM BF4, BMIM PF6 is considered a hydrophobic ionic liquid. BMIM PF6 is a relatively common ionic liquid, in which Novozym ${ }^{\circledR} 435$ has been shown to retain at least $50 \%$ of its activity after 48 $\mathrm{h}$ at $50^{\circ} \mathrm{C}$ [20]. Still, low production were obtained with BMIM PF6, where again this could be caused by low solubility of both substrates in BMIM PF6 (Table 1). Overall, the results with BMIM PF6 correspond well with previous studies on ascorbic acid esterification [8]. In general, it seems that no direct relationships between the hydrophilic/ hydrophobic properties of the ionic liquids and the activity of different enzymes have been established [18]. This indicates that more issues than just hydrophobic/-philic properties and solubility are related to affect the activity of enzyme.

\section{Influence of Initial Concentration of Ascorbic Acid in Ionic Liquid}

Similar to the esterification in the tert-butanol system, an increase in ascorbic acid concentration above its saturation limits increased product concentration significantly. Doubling the ascorbic acid concentration from 0.41 to 0.82 $\mathrm{mmol} / \mathrm{ml}$ increased the productivity from $10.6 \mathrm{~g} / 1$ to $63.4 \mathrm{~g} / \mathrm{l}$ of ester product, which is almost six times increasing. Furthermore, a 6-fold increase in concentration of ascorbic acid to $2.44 \mathrm{mmol} / \mathrm{ml}$ gave an 8 -fold increase in ascorbyl-CLA ester production (94.2 g/l) after $32 \mathrm{~h}$ reaction (Fig. 7).

\section{Effects of Temperature and Pressure on Conversion in Ionic Liquid}

The low volatility of ionic liquids permits the use of higher reaction temperatures. A significant increase in reaction rate was observed when temperature was increased from $55^{\circ} \mathrm{C}$ to $70^{\circ} \mathrm{C}$, and the volumetric productivity was increased by $60 \%$ after $32 \mathrm{~h}$ (Fig. 7). Certainly this could be mostly attributed to the reduction of viscosity due to increase of temperature. On the other hand, the enzymatic activity was surely increased as well following Arrhenius law within the temperature range. Additionally, we also noticed that the use of vacuums to remove water, which was formed during the esterification reaction, did not increase product formation further. The volumetric productivity obtained at atmospheric pressure was $40 \%$ higher than what was obtained at 3 mbars. This could indicate that too much water is removed to keep the enzyme in its active configuration at 3 mbars. It could be also that ionic liquids played an important role to isolate water from the reaction equilibrium. Further study should be conducted to investigate the vacuum effect in a more detail plan.

As an evident conclusion for the ionic liquid system, it should be noticed that it possible to get up to more than 200 


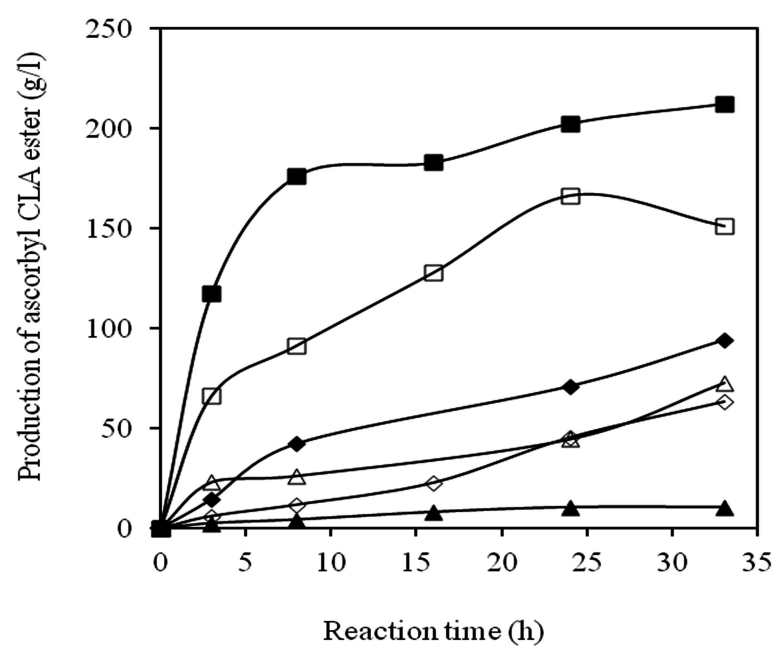

Fig. (7). Optimization of reaction systems. Reaction systems were firstly optimized at $55{ }^{\circ} \mathrm{C}$ under vacuum ( 3 mbar) by varying concentration of ascorbic acid: $0.41 \mathrm{mmol} / \mathrm{ml}(\boldsymbol{\Delta}), 0.82 \mathrm{mmol} / \mathrm{ml}(\quad), 1.62 \mathrm{mmol} / \mathrm{ml}(\triangle), 2.11 \mathrm{mmol} / \mathrm{ml}(\bullet)$. Afterwards, temperature was increased to $70{ }^{\circ} \mathrm{C}$ to evaluated the reaction under vacuum (3 mbar) $(\square)$ or without vacuum $(\mathbf{\square})$, while the concentration of ascorbic acid was kept as $2.11 \mathrm{mmol} / \mathrm{ml}$. In each case of reaction, $15 \%$ of Novozym ${ }^{\circledR} 435$ and $2 \mathrm{mmol} / \mathrm{ml}$ of CLA were applied.

$\mathrm{g} / \mathrm{l}$ productivity in the selected ionic liquid system. This could be six times of that in the traditional solvents. It certainly demonstrates more potentiality of the system for further development.

\section{CONCLUSIONS}

These studies show that ascorbic acid can be esterified with the nutritionally important CLA in an organic solvent system as shown in literature for other esters such as ascorbyl palmitate. More interestingly, this enzymatic esterification was successfully transferred to an ionic liquid system consisting of $t \mathrm{OMA} \cdot \mathrm{TFA}$. The enzymatic reaction in the ionic liquid system was preliminarily optimized. Overall high production up to $200 \mathrm{~g}$ ascorbyl ester/l reaction batch was obtained in comparison with maximum $35 \mathrm{~g} / 1$ for the organic solvent system. This is a significant increasement considering the possibility of the volumetric productivity of the process. On the other hand, the reaction time will be longer for the ionic liquid system. The separation of product could be more difficult also for the ionic liquid system. Therefore, the decision of which one is better should be further evaluated. Obviously the study provides a preliminary evaluation in terms of volumetric productivity for the purpose to inspire more research.

\section{ACKNOWLEDGEMENTS}

The study was financed by the Danish Research Council through the Strategic Food and Health Programme. We thank Inge Holmberg and Maike Timm-Heinrich for assisting the HPLC analysis.

\section{REFERENCES}

[1] Wallace JM, McCabe AJ, Robson PJ, et al. Bioavailability of n-3 polyunsaturated fatty acids (PUFA) in foods enriched with microencapsulated fish oil. Ann Nutr Metab 2000; 44: 157-62.

[2] Let MB, Jacobsen C, Meyer AS. Lipid oxidation in milk, yoghurt, and salad dressing enriched with neat fish oil or pre-emulsified fish oil. J Agric Food Chem 2007; 55: 7802-9.
[3] Yan Y, Bornscheuer UT, Schmid RD. Lipase-catalyzed synthesis of vitamin C faatty acid esters. Biotechnol Lett 1999; 21: 1051-4.

[4] Humeau C, Girardin M, Rovel B, Miclo A. Enzymatic synthesis of fatty acid ascorbyl esters. J Mol Catal B: Enzym 1998; 5: 19-23.

[5] Kuwabara K, Watanabe Y, Adachi S, Nakanishi K, Matsuno R. Synthesis of 6-O-unsaturated acyl L-ascorbates by immobilized lipase in acetone in the presence of molecular sieve. Biochem Eng $\mathrm{J}$ 2003; 16: 17-22.

[6] Song Q, Wei D, Zhou W, Xu W, Yang S. Enzymatic synthesis and antioxidant properties of L-ascorbyl oleate and L-ascorbyl linoleate. Biotechnol Lett 2004; 26: 1777-80.

[7] Zhao H, Zhang Y, Lu F, Bie X, Lu Z, Ning H. Optimized enzymatic synthesis of ascorbyl esters from lard using Novozym 435 in cosolvent mixtures. J Mol Catal B: Enzym 2011; 69: 107-11.

[8] Lee KW, Lee HJ, Cho HY, Kim YJ. Role of the conjugated linoleic acid in the prevention of cancer. Crit Rev Food Sci Nutr 2005; 45: $135-44$.

[9] Whigham LD, Watras AC, Schoeller DA. Efficacy of conjugated linoleic acid for reducing fat mass: a meta-analysis in humans. Am J Clin Nutr 2007; 85: 1203-11.

[10] Yu L. Free radical scavenging properties of conjugated linoleic acids. J Agric Food Chem 2001; 49: 3452-6.

[11] Watanabe Y, Minemoto Y, Adachi S, Nakanishi K, Shimada Y, Matsuno R. Lipase-catalyzed synthesis of 6-O-eicosapentaenoyl Lascorbate in acetone and its autoxidation. Biotechnol Lett 2000; 22: 637-40.

[12] Park S, Viklund F, Hult K, Kazlauskas RJ. Vacuum-driven lipasecatalysed direct condensation of L-ascorbic acid and fatty acids in ionic liquids: synthesis of a natural surface active antioxidant. Green Chem 2003; 5: 715-9.

[13] Adamczak M, Bornscheuer UT. Improving ascorbyl oleate synthesis catalyzed by Candida antarctica lipase B in ionic liquids and water activity control by salt hydrates. Process Biochem 2009; 44: 257-61.

[14] Chen B, Guo Z, Let MB, Lue BM, Xu X. Preparation of CLA ascorbyl ester with improved volumetric productivity by an ionic liquid-based reaction system. Org Biomol Chem 2008; 6: 3196201.

[15] Guo Z, Lue BM, Thomasen K, Meyer AS, Xu X. Predictions of flavonoid solubility in ionic liquids by COSMO-RS: experimental verification, structural elucidation, and solvation characterization. Green Chem 2007; 9: 1362-73.

[16] Song Q, Wei D. Study of Vitamin C ester synthesis by immobilized lipase from Candida sp. J Mol Catal B: Enzym 2002; 18: 261-6.

[17] Zhao H. Effect of ions and other compatible solutes on enzyme activity, and its implication for biocatalysis using ionic liquids. J Mol Catal B: Enzym 2005; 37: 16-25.

[18] van Rantwijk F, Sheldon RA. Biocatalysis in ionic liquids. Chem Rev 2007; 107(6): 2757-85. 
[19] Liu Q, Janssen MHA, van Rantwijk F, Sheldon RA. Roomtemperature ionic liquids that dissolve carbohydrates in high concentrations. Green Chem 2005; 7: 39-42.
[20] Kaar JL, Jesionowski AM, Berberich JA, Moulton R, Russell AJ. Impact of ionic liquid physical properties on lipase activity and stability. J Am Chem Soc 2003; 125: 4125-31.

Received: January 26, 2012

(C) Yang et al.; Licensee Bentham Open.

This is an open access article licensed under the terms of the Creative Commons Attribution Non-Commercial License (http://creativecommons.org/licenses/by-nc/3.0/) which permits unrestricted, non-commercial use, distribution and reproduction in any medium, provided the work is properly cited 